\title{
TUMBUHAN PEWARNA ALAMI KAIN TENUN IKAT SUKU METO DI KECAMATAN NUNKOLO, KABUPATEN TIMOR TENGAH SELATAN
}

\author{
Fransina Thresiana Nomleni, Alan Charis Sabuna, Since Debita Sanam \\ Program studi pendidikan Biologi, Fakultas Keguruan dan IImu Pendidikan Universitas Kristen Artha wacana-Kupang
}

Corresponden author: nomlenifince@gmail.com,

\begin{abstract}
Abstrak:
Penelitian ini bertujuan untuk mengetahui tumbuhan pewarna alami, organ tumbuhan yang digunakan, warna yang dihasilkan, dan proses pengolahan tumbuhan hingga menghasilkan warna. Metode yang digunakan adalah metode deskriptif kualitatif dengan teknik observasi dan wawancara semi struktural. Penelitian ini pada masyarakat Desa Haumeni, Desa Putun dan Desa Nunkolo, Kecamatan Nunkolo, Kabupaten Timor Tengah Selatan. Jumlah informen dalam penelitian ini 30 orang yang terdiri atas kepala Desa, tokoh masyarakat, pengrajin dan masyarakat yang mengetahui tentang pemanfaatan tumbuhan pewarna alami. Hasil penelitian diperoleh 5 jenis tumbuhan pewarna alami yaitu rimpang dari famili Zingiberaceace yaitu Kunyit/Huki (Curcuma domestica L) menghasilkan warna kuning yang diolah dengan cara ditumbuk, warna merah dihasilkan dari kulit batang famili Rubiaceace yakni Mengkudu/Baok'ulu (Morinda citrifolia L) yang direbus, warna hijau dihasilkan dari famili Fabaceace yakni daun kacang Arbila/Koto (Phaseolus lunatus L) yang ditumbuk, warna hitam dihasilkan dari famili Rubiaceace yakni daun Tarum/Taum (Indigofera tinctoria L) yang direndam, dari famili Euphorbiaceae yang diambil adalah daun Pohon Buah Tinta/Meko (Phylantus reticulatus Poir) untuk warna biru diolah dengan direndam dan dicampuran tepung jagung, Selain itu terdapat tumbuhan yang digunakan sebagai bahan tambahan dalam pewarnaan yaitu daging buah kelapa/Noa (Cocos nucifera) dan kapur sirih. Tumbuhan yang digunakan dalam proses perendaman awal adalah Kemiri/Fenu (Aleurites mollucana L) dan Jagung/Pena (Zea Mays L). Tujuan penambahan kapur adalah sebagai penguat warna sehingga tidak mudah luntur. Tumbuhan yang berpotensi sebagai pewarna alami tenun ikat sebagian besar telah dibudidayakan. Tumbuhan yang dibudidayakan adalah Tarum, Kunyit dan kacang Arbila.
\end{abstract}

Kata kunci: Tumbuhan, Organ tumbuhan, Pewarna Alami.

\begin{abstract}
This study aims to determine the natural coloring plants, plant organs used, the colors produced, and the processing of plants to produce colors. The method used is a descriptive qualitative method with semi-structural observation and interview techniques. This research was conducted at the Haumeni Village, Putun Village and Nunkolo Village, Nunkolo District, South Central Timor Regency. The number of informants in this study were 30 people consisting of village heads, community leaders, artisans and the public who knew about the use of natural coloring plants. The results of the study were obtained 5 types of natural coloring plants namely rhizomes of the Zingiberaceace family namely Turmeric / Huki (Curcuma domestica $L$ ) produce yellow color which is processed by pounding, red color is produced from the stem bark of the Rubiaceace family namely Noni / Baok'ulu (Morinda citrifolia L) boiled, the green color is produced from the Fabaceace family which is ground leaves of Arbila / Koto (Phaseolus lunatus L) which are crushed, the black color is produced from the Rubiaceace family namely leaves of Tarum / Taum (Indigofera tinctoria $L$ ) which are soaked, from the Euphorbiaceae family taken are the leaves of the Tree Ink / Meko (Phylantus reticulatus Poir) for blue color is processed by soaking and mixed with corn flour. In addition, there are plants that are used as additives in coloring, namely coconut flesh / Noa (Cocos nucifera) and whiting. Plants used in the initial immersion process are Candlenut / Fenu (Aleurites mollucana $\mathrm{L}$ ) and Corn / Pena (Zea Mays L). The purpose of adding lime is to strengthen the color so it does not fade easily. Most of the plants that have potential as natural dyes for connective weaving have been cultivated. Plants that are cultivated are Tarum, Turmeric and Arbila beans.
\end{abstract}

Keywords : Plants, plant organs, natural dyes. 


\section{Pendahuluan}

Tenun ikat merupakan salah satu seni budaya kain tradisional Provinsi Nusa Tenggara Timur (NTT), yang tumbuh dan berkembang secara turun-temurun dalam masyarakat. Tenun ikat diproduksi hampir di seluruh wilayah Nusa Tenggara Timur, termasuk didalamnya Kecamatan Nunkolo Kabupaten Timor Tengah Selatan. Tenun ikat pada awalnya dibuat untuk memenuhi kebutuhan sehari-hari sebagai busana penutup dan pelindung tubuh, namun akhirnya berkembang untuk kebutuhan adat (pesta, upacara, tarian, perkawinan, kematian dan sebagainya) (Susilawati, 2010).Pembentukan motif tenun lkat diperoleh dari proses pengikatan benang yang kemudian dicelup warna dan bagian yang tidak diikat akan menyerap warna. Pada awalnya benang diwarnai dengan menggunakan pewarna alami. Pewarna alami adalah bahan pewarna yang sebagian besarnya berasal dari tumbuhan. Masyarakat telah mengetahui tumbuh-tumbuhan yang banyak digunakan sebagai pewarna alami tenun ikat diantaranya: Warna merah diperoleh dari bunga pada tumbuhan Hibiscus rosa-senensis $L$ (Kembang sepatu) dan akar dari tumbuhan Morinda citrifolia L (Mengkudu). Warna kuning dapat diperoleh dari rimpang pada tumbuhan Curcuma domestica L. (Kunyit), dan akar pada tumbuhan Solanum lycopersicum $L$ (Terong). Warna hijau diperoleh dari daun pada tumbuhan Pandanus amaryllfolius Roxb (Pandan). Warna biru sampai hitam diperoleh dari daun pada tumbuhan Indigofera tinctoria (Tarum) dan untuk mempertahankan warna diperoleh dari : Aleurites molluccana L (Kemiri), Symplocus sp (Loba) (Handoko, 2004).

Pembuatan kain tenun ikat di Kecamatan Nunkolo masih menggunakan zat pewarna alami yang berasal dari bagian tumbuhan penghasil pewarna (kulit kayu, daun, rimpang dan buah). Sampai sekarang zat pewarna alami masih digunakan terutama pada kain tenun dengan corak tradisional. Tumbuhan sebagai pewarna dalam pembuatan tenun ikat telah lama dikenal oleh masyarakat dengan nama pewarna nabati atau alami. Dalam proses pewarnaan menggunakan tumbuhan, para penenun sudah mengetahui dengan pasti warna yang dihasilkan dari setiap jenis tumbuhan. Kegunaan tumbuhan sebagai pewarna alami ini sangat menguntungkan karena mudah diperoleh, tidak membutuhkan biaya untuk mendapatkannya, bersifat ramah lingkungan dan tidak bersifat toksik terhadap kulit murah dan tahan lama. Penggunaan tumbuhan sebagai pewarna alami ini telah diuji kestabilannya melalui pencucian dengan menggunakan detergen namun tidak luntur (Ati, 2006). Tumbuhan-tumbuhan tersebut sangat beranekaragam dan dapat dijumpai di pekarangan rumah maupun di hutan luas. Pewarnaan benang menggunakan zat warna alami ini disukai karena menimbulkan efek khas yang tidak dapat ditiru oleh zat warna sintetis. Hal inilah yang mendukung kain tenun ikat sebagai produk ekslusif banyak diminati. 
Berdasarkan observasi, warna alami sudah dikenal jauh sebelum ditemukannya pewarna sintesis yang beredar sekarang ini di masyarakat yang menggunakan pewarna sintesis. Oleh karena banyaknya pengunaan pewarna sintesis ini, tidak dapat dipungkiri bahwa pengetahuan generasi muda saat ini, tentang tumbuhan pewarna alami sangat berkurang. Selain itu, masyarakat sudah jarang menggunakan pewarna alami untuk kain tenun tradisional, mengakibatkan tumbuhan yang berpotensi sebagai pewarna alami tenun ikat keberadaanya mulai berkurang. Selain itu informasi jenis tumbuhan pewarna alami dan pemanfaatannya masih minim dan belum terdokumentasi. Dengan demikian, tumbuhan yang berpotensi sebagai pewarna alami dapat dilestarikan dengan baik. Tujuan penelitian ini juga untuk mengetahui tumbuhan pewarna alami, organ atau bagian tumbuhan yang digunakan, warna yang dihasilkan, dan proses pengolahan tumbuhan hingga menghasilkan warna sebagai pewarna kain

tenun

ikat

\section{METODE PENELITIAN}

\section{Waktu dan Lokasi Penelitian}

Penelitian ini dilaksanakan di Kabupaten Timor Tengah Selatan Kecamatan Nunkolo meliputi 3 Desa yaitu : Desa Haumeni, Desa Putun dan Desa Nunkolo, Kecamatan Nunkolo, Kabupatean Timor Tengah Selatan. Penelitian ini dilaksanakan pada bulan Oktober sampai Desember 2016.

\section{Prosedur Kerja}

Penelitian ini menggunakan metode deskriptif. Metode ini merupakan prosedur penelitian kualitatif yang menghasilkan data berupa kata-kata dari orang-orang yang dapat diamati (Moleong, 2000). Teknik yang digunakan dalam penelitian ini adalah teknik observasi langsung di lapangan dan wawancara semi struktural yang mengacu pada daftar pertanyaan yang disiapkan oleh peneliti kepada pengrajin tenun ikat. Prosedurnya meliputi:

1. Tahap Observasi

Melakukan pengamatan pada lokasi penelitian yang ada di Desa Haumeni, Desa Putun dan Desa Nunkolo untuk memperoleh informasi gambaran umum tentang lokasi penelitian.

\section{Tahap Persiapan}

Sebelum melakukan penelitian, persiapan yang perlu dilakukan adalah mempersiapkan alat yang akan digunakan dalam penelitian.

3. Tahap Pelaksanaan di Lokasi Penelitian

a. Melakukan wawancara terhadap informan untuk memperoleh informasi tentang jenis-jenis tumbuhan pewarna alami

b. Responden yang diwawancarai adalah pengrajin tenun ikat terdiri atas kepala Desa, tokoh masyarakat, pengrajin dan masyarakat yang mengetahui tentang pemanfaatan tumbuhan pewarna alami. 
c. Melakukan penjelajahan atau pencarian jenis tumbuhan pewarna alami.

d. Mengamati prosedur pengolahan bagian atau organ tumbuhan hingga mengasilkan warna yang diinginkan oleh pengrajin tenun ikat.

4. Tahap Pengumpulan Data

Pengumpulan data dilakukan dengan cara mencatat semua jenis tumbuhan yang digunakan sebagai pewarna alami di setiap desa.

5. Memasang label pada jenis tumbuhan yang sudah diketahui namanya dan melakukan identifikasi pada jenis tumbuhan yang belum diketahui namanya.

6. Mencatat bagian atau organ tumbuhan yang digunakan sebagai pewarna alami

7. Mencatat cara pengolahan yang dilakukan oleh pengrajin tenun ikat hingga menghasilkan warna.

\section{Analisis Data}

Data yang diperoleh dari observasi dan wawancara yaitu jenis-jenis tumbuhan pewarna alami, bagian atau organ yang digunakan, warna yang dihasilkan serta prosedur pengolahan hingga menghasilkan warna disajikan dalam tabulasi, selanjutnya melakukan identifikasi terhadap terhadap jenis tumbuhan jika terdapat tumbuhan yang tidak diketahui namanya.

\section{HASIL DAN PEMBAHASAN}

\section{Hasil}

Berdasarkan hasil wawancara dengan responden dari tiga Desa yang ada di Kecamatan Nunkolo, yaitu : Desa Haumeni, Desa Nunkolo dan Desa Putu diketahui bahwa sampai saat ini masyarakat masih memanfaatkan tumbuh-tumbuhan yang berfungsi sebagai pewarna alami dan tetap melestarikan pengetahuan yang berasal dari leluhur. Tumbuhan yang digunakan sebagai pewarna alami diperoleh dari beberapa bagian tumbuhan yaitu: daun, biji, rimpang dan kulit kayu yang diolah secara sederhana untuk menghasilkan warna. Jenis-jenis tumbuhan yang digunakan sebagai pewarna alami dalam penelitian ini dapat dilihat pada Tabel 1.

Tabel 1. Nama tumbuhan, Organ tumbuhan, Cara pengolahan dan Warna yang dihasilkan

\begin{tabular}{ccccc}
\hline $\begin{array}{c}\mathbf{N} \\
\mathbf{0}\end{array}$ & $\begin{array}{c}\text { Nama Lokal/ Nama } \\
\text { Indonesia/ Nama } \\
\text { Ilmiah tumbuhan }\end{array}$ & $\begin{array}{c}\text { Organ } \\
\text { Tumbuhan }\end{array}$ & $\begin{array}{c}\text { Cara } \\
\text { Pengolahan } \\
\text { tinctoria L) }\end{array}$ & $\begin{array}{c}\text { Warna } \\
\text { Yang } \\
\text { Dihasilkan }\end{array}$ \\
\hline 1. & $\begin{array}{c}\text { Taum/Tarum (Indigofera } \\
\text { hitam }\end{array}$ & Daun & direndam & \\
& ( & & & \\
\end{tabular}


2.

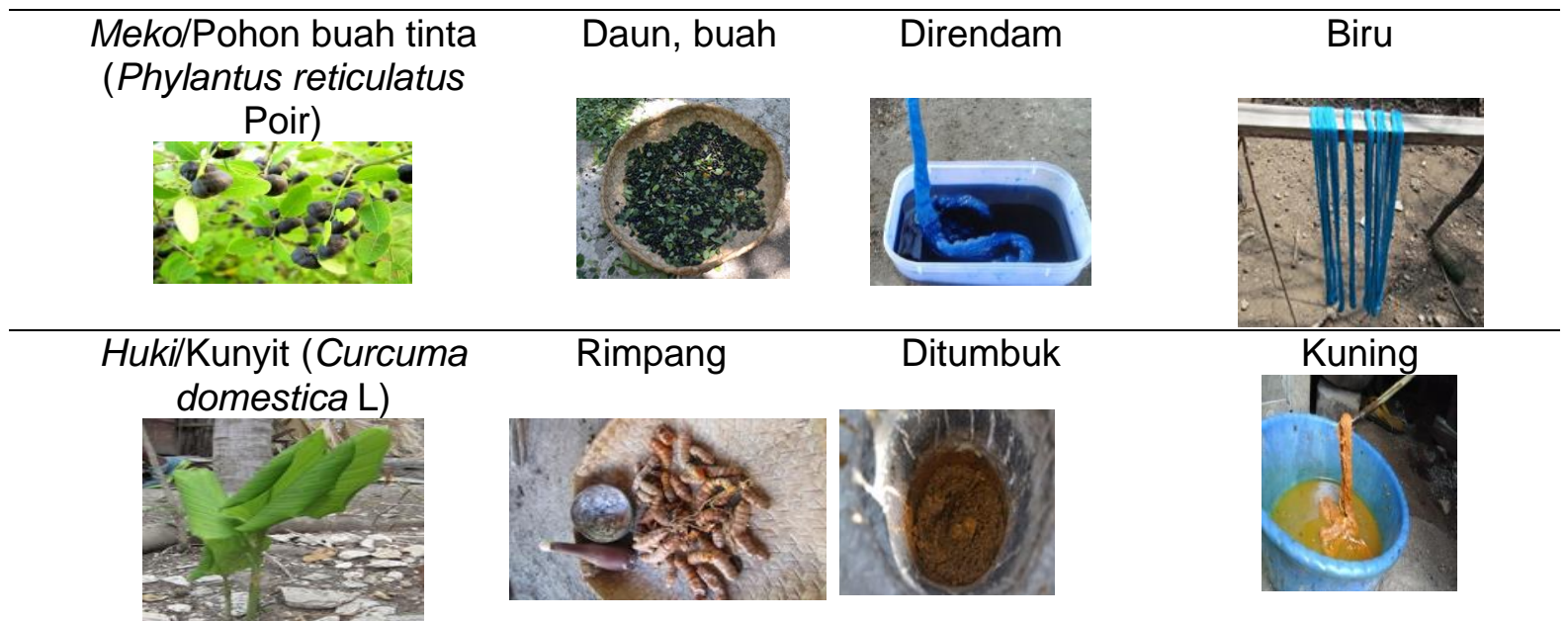

4.
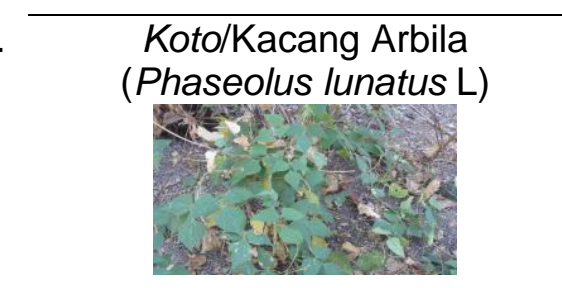

Daun

Ditumbuk
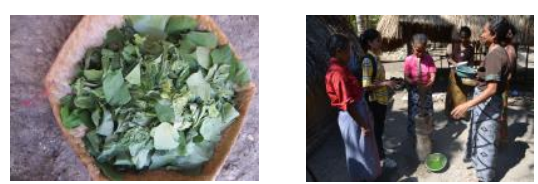

Hijau

5.
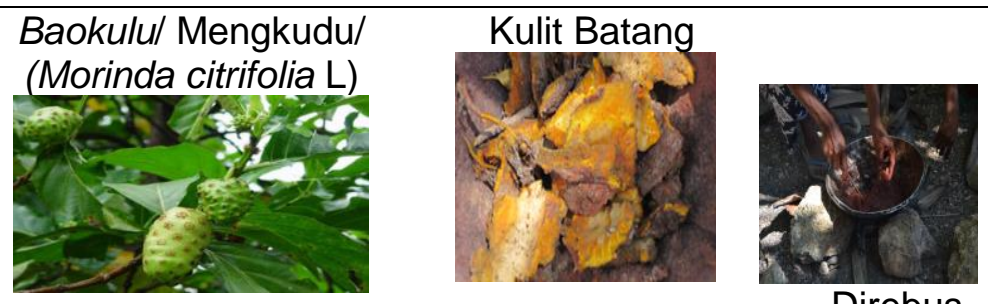

Direbus

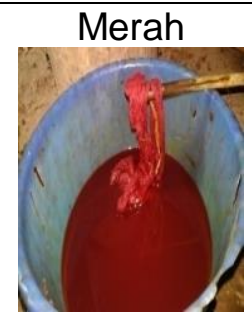

Selain tumbuhan pewarna yang digunakan terdapat tumbuhan yang digunakan dalam proses perendam awal benang sebelum diwarnai. Tumbuhan yang digunakan ada 3 tumbuhan antara lain kelapa, kemiri, dan jagung yang dapat dilihat pada Tabel 2.

Tabel 2.Tumbuhan yang Digunakan dalam Proses Perendaman Awal

\begin{tabular}{cccc}
\hline $\mathbf{N}$ & $\begin{array}{c}\text { Nama Lokal/ Nama } \\
\text { Indonesia/ Nama } \\
\text { IImiah }\end{array}$ & $\begin{array}{c}\text { Organ yang } \\
\text { Digunakan }\end{array}$ & Perendaman Awal \\
\hline 1 & $\begin{array}{c}\text { buah kelapa/Noa } \\
\text { (Cocos nucifera })\end{array}$ & Daging buah \\
& &
\end{tabular}




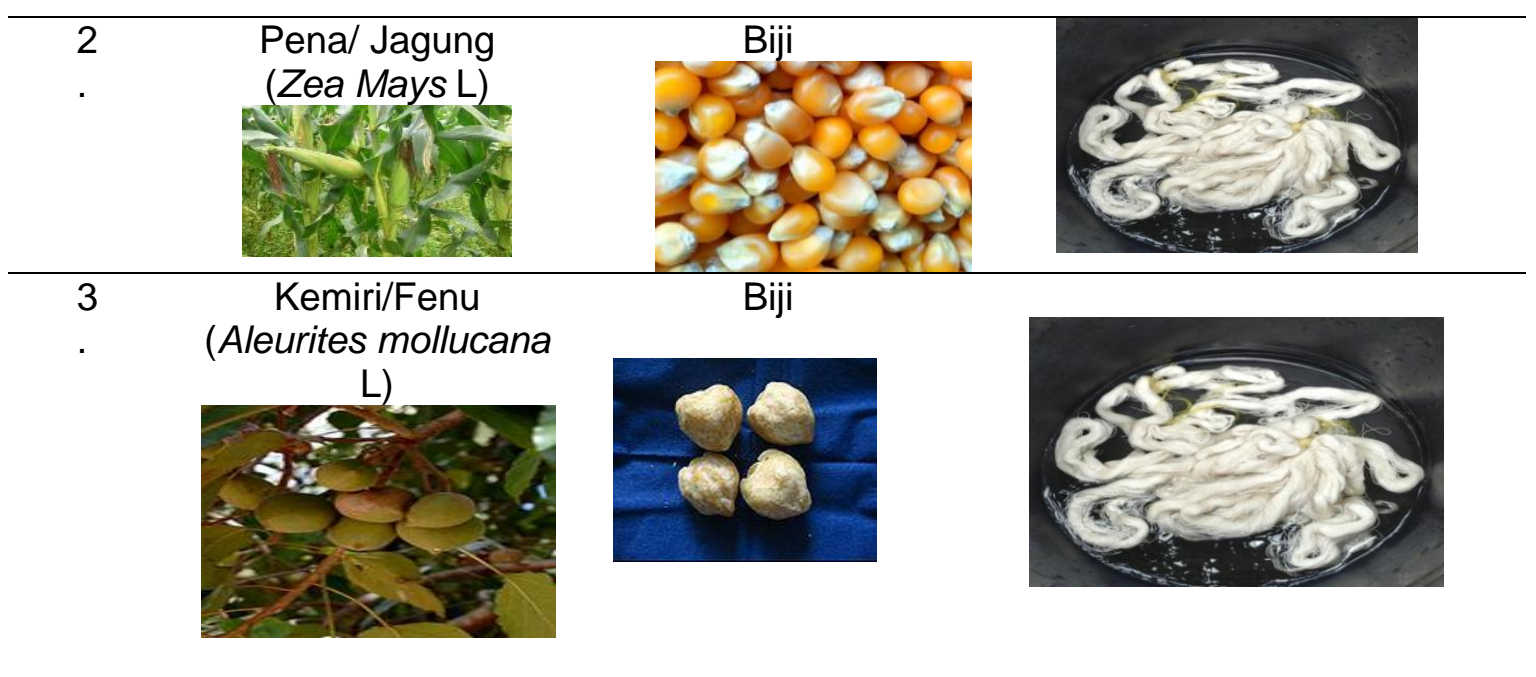

Sementara dalam proses perendaman benang, digunakan bahan tambahan yaitu kapur sirih, yang berfungsi untuk menjaga kekuatan benang agar benang yang diwarnai tidak mudah luntur. Dalam penelitian ini bahan tambahan tersebut dapat dilihat pada Gambar 1.

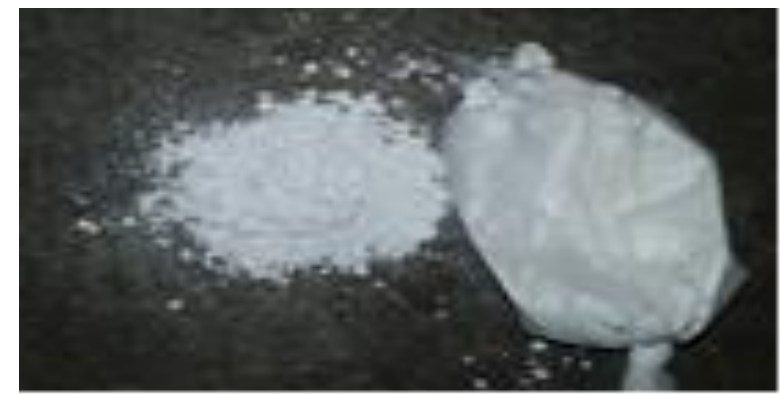

Gambar 1.Kapur

Untuk proses pengolahan tumbuhan menjadi pewarna alamai dapat dilihat pada Tabel 3.

Tabel 3. Proses Pengolahan Tumbuhan menjadi pewarna alami

\begin{tabular}{ll}
\hline Nama Tumbuhan & Cara Pengelolaan \\
\hline Tarum & $\begin{array}{l}\text { Daun tarum direndam selama 4-5 hari. Daun tarum yang } \\
\text { direndam di remas-remas untuk mendapatkan hasil } \\
\text { rendaman. Air rendaman ditambahkan buah kelapa dan } \\
\text { kapur kemudian benang dicelupkan sebanyak 3 kali }\end{array}$ \\
\hline Mengkudu & $\begin{array}{l}\text { Kulit mengkudu ditumbuk hingga hancur ditambahkan } \\
\text { dengan air direbus bersama benang selama 1-2 jam, } \\
\text { kemudian diangkat dan dijemur. }\end{array}$ \\
\hline Daun kacang & $\begin{array}{l}\text { Daun kacang Arbila diambil satu bakul ditumbuk sampai } \\
\text { halus kemudian masukan benang dan ditumbuk bersamaan } \\
\text { dikeluarkan diremas-remas agar warna benang merata, } \\
\text { direndam dengan air 1 gelas salama 3-4 jam baru diangkat } \\
\text { dan dijemur. }\end{array}$ \\
\hline
\end{tabular}


Kunyit Rimpang kunyit ditumbuk sampai hancur masukan benang dan ditumbuk bersama benang, dikeluarkan kemudian diremas-remaskan ditambahkn air dan rendam selama 3-4 jam diangkat dan dijemur.

Pohon buah tinta Buah pohon tinta diambil sebanyak 1 nyiru kemudian diremas-remas kemudian ditambahan tepung jagung dan ditambahkan air direndam selama 3 hari, masukan benang dan direndam selama 3-4 jam baru diangkat dan dijemur

\section{Pembahasan}

Masyarakat Kecamatan Nunkolo merupakan salah satu suku di Nusa Tenggara Timur, yang masih menggunakan pewarna alami dari tumbuhan sebagai pewarna alami tenun ikat. Tumbuhtumbuhan ini muda didapat di sekitar lingkungan tempat tinggal dan sebenarnya merupakan pengetahuan yang dikembangkan dari dahulu kala. Organ yang dimanfaatkan untuk pewarna kain tenun adalah rimpang, kulit batang, buah dan daun. Warna yang dihasilkan oleh tumbuhan bervariasi bergantung dari jenis tumbuhan tersebut. Penggunaan pewarna alami dari tumbuhan, untuk menghasilkan warna maka harus diolah terlebih dahulu. Bagian organ tumbuhan yang digunakan sebagai pewarna kain tenun ikat dipotong-potong hingga berukuran kecil kemudian dihancurkan menjadi halus, organ tumbuhan yang sudah dihaluskan dimasukkan ke dalam air mendidih, selanjutnya dimasukkan ke dalam suatu wadah yang berukuran besar. Benang yang telah diikat dimasukkan ke dalam air rebusan tadi, kemudian benang tersebut dibolak-balik hingga warna menyerap rata pada serat-serat benang. Apabila warna sudah menyerap rata, maka benang tersebut di jemur hingga kering.

Bagian tumbuhan yang digunakan oleh masyarakat di Desa Haumeni, Desa Putun dan Desa Nunkolo, Kecamatan Nunkolo, Kabupaten Timor Tengah Selatan sebagai pewarna alami yaitu: daun Tarum (Indigofera tinctoria L), daun dari pohon buah tinta (Phylantus reticulatus Poir), rimpang pada kunyit (Curcuma domestica L), daun dari Kacang Arbila (Phaseolus lunatus L), dan kulit batang dari mengkudu (Morinda citrifolia L). Menurut Hakim (1999), Zzat warna alami adalah zat yang diperoleh dari tumbuhan baik secara langsung maupun tidak langsung. Warna alami diperoleh dari bagian-bagian tumbuh-tumbuhan seperti akar (rimpang), batang, daun, bunga dan buah dengan warna yang dihasilkan bervariasi. Timor Tengah Selatan mengenal lima macam warna yang dihasilkan dari tumbuhan yang termasuk di dalam lima famili. Warna kuning berasal dari famili Zingiberaceae (Curcuma domestica L), warna merah berasal dari famili Rubiaceae (Morinda citrifolia L), warna hijau berasal dari famili Fabaceace yakni daun koto/kacang arbila (Phaseolus lunatus L), warna hitam berasal dari famili Papilionaceae (Indigofera tinctoria L), dan warna biru berasal dari famili Euphorbiaceae (Phylantus reticulatus 
Poir). Selain tumbuhan pewarna alami, terdapat dua jenis tumbuhan yang digunakan untuk perendaman awal sebelum masuk pada tahap pewarnaan tenun ikat. Tujuan perendaman awal ini agar benang yang diwarnai tidak mudah luntur.

Menurut Heyne (1987), Warna dapat diperoleh dari produk tumbuhan, pada jaringan tumbuhan terdapat pigmen tumbuhan penimbul warna yang berbeda. Golongan pigmen tumbuhan dapat berbentuk klorofil, karotenoid, antosianin dan tanin. menambahkan bahwa, Khlorofil (chlorophi) adalah kelompok pigmen fotosintesis yang terdapat dalam tumbuhan, menyerap cahaya merah, biru dan ungu, serta merefleksikan cahaya hijau yang menyebabkan tumbuhan memperoleh ciri warnanya umumnya terdapat pada bagian daun. Karotenoid adalah pigmen tumbuhan yang menghasilkan warna kuning, orange sampai merah terdapat pada akar dan kulit kayu (pepangan). Antosianin yaitu pigmen yang dapat memberikan warna merah, biru, atau keunguan, kebanyakan terdapat pada bunga dan kulit kayu (pepangan). Tanin ialah pigmen pembentuk warna gelap biasa .

Berdasarkan hasil penelitian, proses pengolahan tumbuhan pewarna alami oleh masyarakat di Kecamatan Nunkolo masih tergolong tradisional. Menurut Sutara (2008), warna alami yang baik dihasilkan dengan cara perebusan atau perendaman secara langsung. Dalam penelitian ini dapat dilihat proses pengambilan tumbuhan pewarna sampai pada tahap pewarnaan produk.

1. Warna hitam, Tumbuhan dipetik bagian daun sebanyak satu karung kemudian direndam pada 10 liter air selama 1 minggu, setelah 1 minggu rendaman akan menghasilkan warna hitam. Benang direndam secara berulang kali hingga benang merata berwarna hitam, kemudian ditambahkan daging buah kemiri serta kapur dan dicelup secara berulang dengan tujuan agar benang yang diwarnai tidak mudah luntur, selanjutnya dikeringkan dan diproses untuk penenunan.

2. Warna biru, Tumbuhan dipetik bagian daun sebanyak 1 nyiru, direndam selama 3 malam pada 5 liter air. Setelah memperoleh larutan biru ditambahkan tepung jagung dengan tujuan untuk menjaga kekuatan benang yang akan direndam agar tidak mudah luntur, kemudian benang direndam secara berulang kali hingga benang merata berwarna biru, selanjutnya dikeringkan dan diproses untuk penenunan.

3. Warna merah. Tumbuhan diambil bagian kulit batang menggunakan parang sebanyak 8 potongan, kemudian ditumbuk sampai hancur lalu dicampur dengan air sebanyak $5 \mathrm{ml}$ kemudian dipanaskan selama 2 jam, hingga berwarna merah, benang dimasukkan ke dalam rebusan dan dibiarkan hingga warna merah merata pada setiap helaian benang, selanjutnya dikeringkan dan diproses untuk penenunan.

4. Warna hijau. Tumbuhan dipetik bagian daunnya sebanyak 1 karung atau 1 nyiru dihaluskan atau ditumbuk bersama benang dan diremas-remas hingga berwarna hijau merata pada setiap helaian benang, selanjutnya dikeringkan dan diproses untuk penenunan.

5. Warna kuning. Tumbuhan diambil bagian rimpang sebanyak $1 \mathrm{Kg}$ atau 1 nyiru ditumbuk bersama benang secara berulang kali dan ditambahkan 1 sendok kapur sirih diaduk hingga warna kuning merata pada setiap helaian benang, selanjutnya dikeringkan dan diproses untuk penenunan. 
Berdasarkan observasi dan wawancara dapat diketahui bahwa tindakan konservasi tradisional tumbuhan pewarna alami tenun ikat secara tidak langsung telah dilakukan. Konservasi tersebut yaitu tidak menggunakan tumbuhan secara keseluruhan untuk digunakan sebagai pewarna alami. Penggunaan bagian tumbuhan yang termasuk pohon hanya mengambil bagian tumbuhan tertentu seperti hanya mengambil daun pada tanaman kacang Arbila, kulit kayu pada mengkudu, sedangkan tumbuhan herba dan semak yaitu dengan mengambil daun tarum, rimpang kunyit dan daun pada pohon buah tinta. Dengan mengambil bagian tertentu dari tumbuhan maka tumbuhan tersebut akan tetap hidup dan dapat dimafaatkan lagi. Konservasi lain yang dilakukan responden adalah jika tumbuhan pewarna alami tenun ikat berasal dari tumbuhan liar, tindakan pengambilan bagian tumbuhan tidak ditempat yang sama melainkan mencari di tempat lain, sehingga tumbuhan liar tersebut tidak punah. Dengan adanya konservasi tradisional tersebut maka tumbuhan pewarna alami tenun ikat tetap tersedia. Prinsip konservasi adalah usaha-usaha yang secara sadar dilakukan untuk memelihara sumber daya untuk jangka yang tidak terbatas, sehingga keberlanjutan sumber daya akan dapat bertahan terhadap perubahan konteks sosial, ekonomi, agama, dan teknologi modern (Heyne, 1987).

\section{PENUTUP}

\section{Kesimpulan}

Tumbuhan yang dimanfaatkan sebagai sumber pewarna alami oleh masyarakat di Kecamatan Nunkolo, Kabupaten Timor Tengah Selatan terdiri dari lima jenis yang termasuk dalam lima famili yaitu: Warna kuning berasal dari famili Zingiberaceae (Curcuma domestica L), warna merah berasal dari famili Rubiaceae L), warna hijau berasal dari dari famili Fabaceace yakni daun Kacang Arbila/Koto (Phaseolus lunatus L), warna (Morinda citrifolia hitam berasal dari famili Rubiaceae (Indigofera tinctoria L), dan warna biru berasal dari famili Euphorbiaceae (Phylantus reticulatus Poir). Bagian tumbuhan pewarna alami yang dimanfaatkan meliputi: rimpang (Curcuma domestica L), kulit batang (Morinda citrifolia L), daun tarum (Indigofera tinctoria L) pohon buah tinta (Phylantus reticulatus Poir) dan daun kacang Arbila/Koto (Phaseolus lunatus L). Warna yang dihasilkan oleh tumbuhan pewarna alami meliputi : rimpang (Curcuma domestica L) menghasilkan warna kuning, kulit batang (Morinda citrifolia L menghasilkan warna merah), daun (Indigofera tinctoria L) menghasilkan warna hitam, (Phylantus reticulatus Poir) menghasilkan warna biru dan (Phaseolus lunatus $\mathrm{L}$ ) menghasilkan warna hijau. Proses pengolahan bagian atau organ tumbuhan yang digunakan sebagai pewarna alami kain tenun ikat yaitu : Tumbuhan penghasil warna hitam dipetik bagian daun kemudian direndam, ditambahkan kemiri dan lumpur pekat. Tumbuhan penghasil warna biru dipetik bagian daun ditumbuk dan direndam, ditambahkan tepung jagung akan menjadi larutan berwarna biru. Tumbuhan penghasil warna merah diambil bagian kulit batang, kemudian ditumbuk sampai hancur lalu dipanaskan bersama benang. Tumbuhan penghasil warna hijau dipetik bagian daunnya dihaluskan atau ditumbuk bersama benang hingga berwarna hijau. Tumbuhan penghasil warna kuning diambil bagian rimpang ditumbuk dan ditambahkan kapur sirih agar menjadi berwarna kuning pekat. 


\section{Ucapan Terima Kasih}

Kami mengucapkan terima kasih kepada pihak-pihak antara lain: Kepala Desa, tokoh masyarakat yang, pengrajin tenun ikat (Kelompok tenun), masyarakat di Kecamatan Nunkolo, yaitu Desa Haumeni, Desa Nunkolo Dan Desa Putu dan semua pihak yang telah membantu sehingga penelitian ini dapat diselesaikan dengan baik.

\section{DAFTAR PUSTAKA}

Ati, N. 2006. Komposisi dan Kandungan Pigmen Tumbuhan Pewarna Alami di Kabupaten Timor Tengah Selatan Propinsi Nusa Tenggara Timur. UKSW Jurnal Indo. J. Chem., 6 (3), 325-331. Salatiga.

Benu, M. J. 2011. Identifikasi Tumbuhan Pewarna Alami Dan Pemanfaatannya Pada Pembuatan Kain Tenun Ikat Di Desa Kuanheum Kecamatan Am Abi Oefeto. UKAW. Kupang.

Dinas Pendidikan dan Kebudayaan. 2005. Tenun Ikat Suku dawan Asal Kabupaten Timor Tengah Selatan. UPTD Museum daerah Provinsi Nusa Tenggara Timur.

Handoko, C. 2004. Kajian Distribusi Ekologis Jenis-Jenis Penghasil Bahan Pewarna di Nusa Tenggara Timur. Prosiding Ekspose Hasil-Hasil Penelitian Balai Penelitian dan Pengembangan Bali dan Nusa Tenggara. Waingapu, 4 Desember 2004.

Hakim, E.H., Sjamsul, A.A., Lukman, M., Maolana, S.Y., \& Didi, M. 1999. Zat warna alami: Retrospek dan Prospek. Makalah Seminar Bangkitnya Warna-Warna Alam. Yogyakarta.

Harborne, J.B. 1996. Metode Fitokimia (Terjemahan). ITB. Bandung.

Heyne, K. 1987. Tumbuhan Berguna Idonesia. Volume III. Pradnya Paramita.

Moleong, L. 2000. Metodologi Penelitian Kualitatif. PT. Remaja Rosadakarya. Bandung.

Susilawati, A.P.D. 2010. Peranan Museum Nusa Tenggara Timur Dalam Pembelajaran Dan Pelestarian Tenun. Universitas Indonesia. Depok.

Sutarno, S. 2001. Tumbuhan Penghasil Alami dan Pemanfaatannya Dalam Kehidupan Suku Meyah di Desa Yoom Nuni Manokwari. Universitas Negeri Cederawasih. Manokwari.

Van Steenis, C.G.G.J. 2008. Flora. PT. Pradnya Paramita. Jakarta. 